\title{
Pharmacokinetics and metabolism of idebenone in healthy male subjects
}

\author{
Michael Bodmer • Pierre Vankan • Manfred Dreier • \\ Klaus W. Kutz • Jürgen Drewe
}

Received: 28 July 2008 / Accepted: 19 November 2008 /Published online: 6 January 2009

(C) Springer-Verlag 2008

\begin{abstract}
Purpose Idebenone is a synthetic analogue of ubiquinone that may be beneficial in the treatment of Friedreich's ataxia. Since in previous pharmacokinetic trials only lower doses were studied, it was the aim of this study to evaluate the pharmacokinetics of idebenone in higher doses of up to $2,250 \mathrm{mg} / \mathrm{day}$.

Methods In this open, randomized trial, 25 healthy male subjects received first either a single oral dose of $150 \mathrm{mg}$ or $750 \mathrm{mg}$ of idebenone, then the same dose given at 8 -h intervals for 14 days.

Results Idebenone and its metabolites appeared in the plasma quickly. Over $99 \%$ of parent idebenone was metabolized, indicating a high first-pass effect. $\mathrm{C}_{\max }$ and $\mathrm{AUC}_{0-\mathrm{t}}$ values for parent idebenone and its metabolites increased in a dose-proportional manner. There was

Competing interest: P.V. is employee of Santhera Pharmaceuticals, K. W.K. is an independent consultant to Santhera Pharmaceuticals, J.D. received a research grant from Santhera Pharmaceuticals, M.B. and M. D. have no conflict of interest.
\end{abstract}

M. Bodmer $\cdot$ M. Dreier $\cdot$ J. Drewe

Department of Clinical Pharmacology, University Hospital Basel,

Basel, Switzerland

K. W. Kutz

AccelPharm,

Basel, Switzerland

P. Vankan $\cdot$ K. W. Kutz

Santhera Pharmaceuticals (Switzerland) Ltd,

Liestal, Switzerland

J. Drewe $(\square)$

Clinical Pharmacology and Toxicology,

University Hospital Basel,

Hebelstr. 2,

CH-4031 Basel, Switzerland

e-mail: juergen.drewe@unibas.ch virtually no accumulation of parent drug or metabolites following multiple dosing.

Conclusions Idebenone exhibited dose-dependent pharmacokinetics in daily doses up to $2,250 \mathrm{mg}$. In $6 / 14$ subjects, adverse events of mild to moderate severity were observed.

Keywords Idebenone $\cdot$ Friedreich's ataxia .

Electron transport $\cdot$ Humans $\cdot$ Pharmacokinetics

\section{Introduction}

Friedreich's ataxia (FA) is the most prevalent autosomal recessive neurodegenerative disorder, characterized by disabling limb ataxia, weakness, sensory loss, skeletal deformities, and hypertrophic cardiomyopathy [1]. FA is caused by mutations in the FRDA gene located on chromosome $9 \mathrm{q} 13$. The product of the gene is frataxin, a ubiquitous $18-\mathrm{kDa}$ soluble mitochondrial protein with 210 amino acids. The most frequent mutation is the expansion of a GAA trinucleotide repeat located within the first intron of the gene, leading to a deficiency of mitochondrial frataxin [2]. There is evidence that frataxin is involved in the assembly of iron-sulfur complexes. Reduced levels of frataxin diminish the activities of iron-sulfur clustercontaining enzymes such as complex I and III in the mitochondrial electron transport chain (ETC), resulting in decreased oxidative phosphorylation as well as intramitochondrial iron accumulation and production of free radicals in patients with FA [3, 4]. Deficiency of ATP synthesis [5] and oxidative stress [6] in the pathology of FA have led to the hypotheses that compounds that support the mitochondrial ETC and cellular ATP generation, coupled with antioxidant qualities, such as idebenone, would offer a potential treatment for patients with FA [7]. Currently, there 
is no cure for this disease, and treatments are limited to supportive medical care.

Idebenone [2,3-dimethoxy-5-methyl-6-(10-hydroxydecyl)21,4-benzoquinone; Fig. 1a] is a synthetic analogue of ubiquinone, a vital cell membrane antioxidant and essential constituent of the ETC. Suno et al. proposed as early as 1984 that idebenone inhibits lipid peroxidation and consequently protects cell membranes and mitochondria from oxidative damage [8,9]. Idebenone also interacts with the ETC, preserving ATP formation and cerebral metabolism [10]. Due to its ability to support mitochondrial energy production and its antioxidant action, idebenone was initially evaluated in Japan for the treatment of cognitive disorders and Alzheimer's disease [11]. Large clinical trials showed that idebenone was safe and well tolerated in these patients [12-14], but lack of improvement in cognitive function led to the termination of development for this indication. The favorable safety profile of idebenone and its dual mechanism of action have

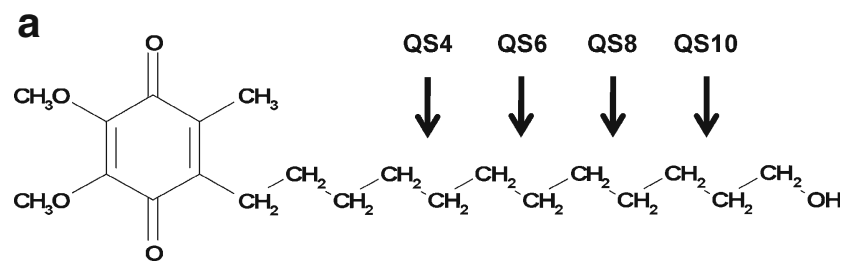

b

Idebenone

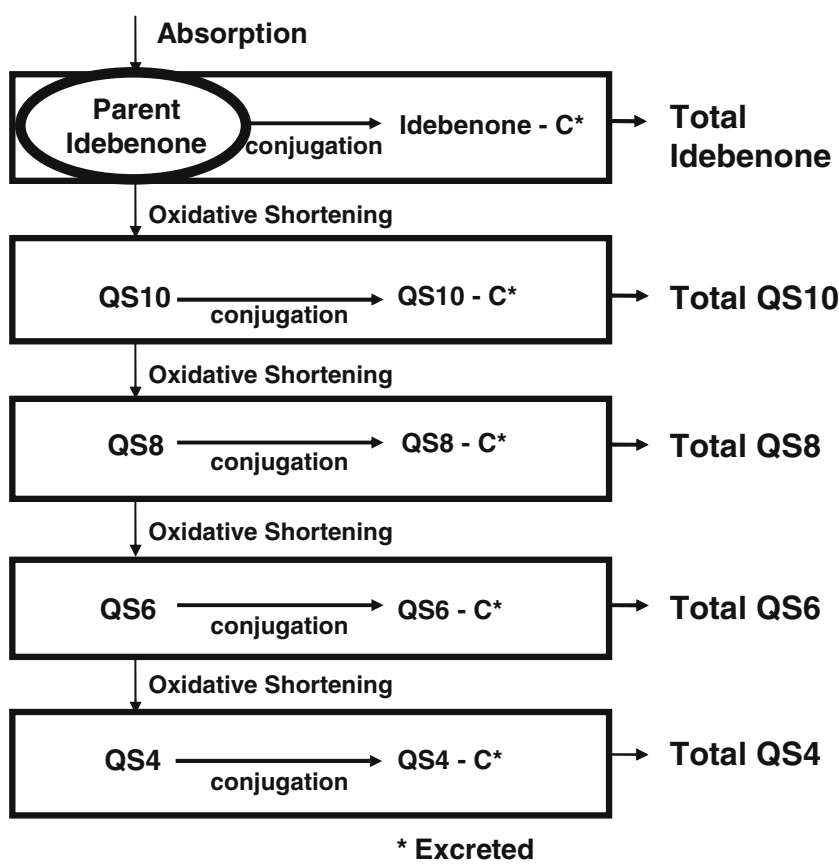

Fig. 1 a Structural formula of parent idebenone. b Parent idebenone is metabolized through side-chain shortening to QS10, QS8, QS6, and QS4. Idebenone and its metabolites exist free or conjugated $(C)$ to sulfates and glucuronides led to investigation of its use in other neurodegenerative diseases with mitochondrial impairment, most notably FA.

Idebenone has been shown to reduce markers of oxidative DNA damage in patients with FA [6]. Several open-label studies found that $5 \mathrm{mg} \mathrm{kg}^{-1}$ day $^{-1}$ of idebenone reduced cardiac hypertrophy but had no consistent effect on neurological symptoms at this dose level [15-17]. Other authors showed that higher doses of idebenone may be necessary for patients to experience the full clinical benefit of idebenone treatment, particularly as it relates to improvements in neurological function [16, 18-21]

Information on pharmacokinetics and metabolism of idebenone is limited, particularly with regard to the pharmacologically active parent idebenone. Parent idebenone is rapidly metabolized through oxidation and sidechain shortening to inactive metabolites QS10, QS8, QS6, and QS4 (Fig. 1b) [22]; both parent idebenone and its metabolites exist either free or conjugated to sulfates and glucuronides. The analytical methods published to date were not sensitive enough to reliably measure parent idebenone, and therefore, only the total amount of idebenone (parent drug + conjugated idebenone) in plasma was determined in the past [23]. In a recent study by Di Prospero et al. [3], safety and pharmacokinetics of highdose idebenone in FA patients were investigated. However, neither plasma levels of parent idebenone nor urine excretion data of idebenone or its metabolites were reported. Therefore, the goals of the present study were to use a newly developed analytical method with greater sensitivity and specificity for pharmacologically active parent idebenone to more accurately investigate the pharmacokinetics and metabolism of idebenone (parent drug and metabolites) and to evaluate the safety of idebenone, administered in doses of up to $2,250 \mathrm{mg}$ daily for 2 weeks, in healthy male subjects.

\section{Methods}

Subjects

Healthy Caucasian male subjects aged between 18 and 45 years were eligible for enrollment if they had a body mass index of $19-29 \mathrm{~kg} / \mathrm{m}^{2}$. Subjects with hypertension, hypotension, a history of alcohol abuse or drug addiction, a current practice of smoking $>10$ cigarettes/day, prior donation of blood within 60 days, prior receipt of blood products within 1 year, relevant allergy, mental handicap, legal incapacity, or clinically important psychiatric illness were excluded. Limited use of paracetamol (acetaminophen) was permitted during this study. Use of all other medications or vitamins was prohibited from 14 days before the study began through the conclusion of the study. 
Ethical conduct of the study

The study was performed at the Department of Clinical Pharmacology, University Hospital, Basel, Switzerland, between July 2005 and December 2005. Subjects gave written informed consent before any study-related activities were carried out. The clinical study protocols and written informed consent form were approved by the State Ethical Committee (Ethische Kommission beider Basel) and the national drug agency (Swissmedic). The studies were performed in accordance with the Declaration of Helsinki, Guidelines on Good Clinical Practice, and followed the Guidelines of the International Conference of Harmonization.

\section{Study design}

This was an open-label, randomized, parallel-group study conducted at a single center. Idebenone was administered as 150-mg film-coated tablet [SNT-MC17; Santhera Pharmaceuticals (Switzerland)]. Each dose consisted of either a single $150-\mathrm{mg}$ idebenone tablet orally (group A) or $5 \times$ 150 -mg idebenone tablets $(750 \mathrm{mg}$ ) orally (group B). The dosing schedule was the same for subjects in both groups. On day 1 , each subject received a single idebenone dose $(150 \mathrm{mg}$ or $750 \mathrm{mg})$ after a continental breakfast that consisted of $160 \mathrm{~g}$ bread, $20 \mathrm{~g}$ butter, $25 \mathrm{~g}$ jam, $200 \mathrm{ml}$ of fruit tea or coffee, $50 \mathrm{~g}$ whole milk, and $180 \mathrm{~g}$ fruit yogurt (797 kilocalories, $10 \%$ protein, $28 \%$ fat, $62 \%$ carbohydrates). After a wash-out period of 7 days, subjects received idebenone doses three times a day (group A: $450 \mathrm{mg}$ total daily dose; group B: $2,250 \mathrm{mg}$ total daily dose) at 8 -h intervals for 14.3 days. The morning dose was always given after a continental breakfast.

On both day 1 and day 22, blood samples $(5 \mathrm{~mL})$ were taken before the first administration of idebenone $(-15 \mathrm{~min})$ and $0.33,0.67,1,1.33,1.67,2,2.33,2.67,3,3.5,4,4.5,5$, $6,8,12,16,24,36,48,60,72$, and $96 \mathrm{~h}$ thereafter. Samples were also collected on day 8 (first day of thrice daily dosing), day 10 , day 12 , day 14 , day 16 , day 18 , and day 20, always before the morning drug administration. Samples were taken by an indwelling catheter up to the 16-h sample and by individual venous punctures thereafter. Each sample was collected into a lithium-heparin-containing tube (Sarstedt, Nümbrecht, Germany) and was immediately put on ice and centrifuged at $1,500 \mathrm{~g}$ for $10 \mathrm{~min}$ at $4^{\circ} \mathrm{C}$ within $30 \mathrm{~min}$ after sampling. Two aliquots were separated and stored in polypropylene tubes at $-80^{\circ} \mathrm{C}$, with a minimum volume of $1.5 \mathrm{~mL}$ of plasma per tube, until plasma level determinations were carried out.

Urine was collected quantitatively. The urine volume was measured and an aliquot of approximately $25 \mathrm{~mL}$ was separated and stored in a polypropylene tube at $-80^{\circ} \mathrm{C}$ until determinations were carried out. Urine samples for pharmacokinetic assessment were collected immediately before the first administration of idebenone on day 1 (time 0 ) and over 12-h intervals $(0-12,12-24,24-48,48-72$, and 72 $96 \mathrm{~h}$ ) thereafter. A final sample was collected over the $8 \mathrm{~h}$ following the final dose of idebenone on day 22 .

Safety assessments, including adverse-event monitoring, vital signs, 12-lead electrocardiograms, and laboratory values (hematology, serum chemistry, and urinalysis), were performed during the course of the study.

Analysis of idebenone concentrations

Parent idebenone in plasma Plasma samples were delivered to a commercial analytical laboratory (Inovalab, Reinach, Switzerland) in deep-frozen state on dry ice and stored at about $-80^{\circ} \mathrm{C}$. After thawing, $10 \mu \mathrm{L}$ of EDTA (pH 7, $37.7 \mathrm{mg} / \mathrm{ml}$ ) solution was added to each sample $(0.150 \mathrm{~mL})$ to avoid spontaneous degradation of conjugated metabolites to parent idebenone. Thereafter, $300 \mu \mathrm{L}$ of internal standard (deuterium-labeled idebenone; idebenone- $\mathrm{d} 3$ dissolved in absolute methanol) was added. After centrifugation for at least $45 \mathrm{~min}$ at $4^{\circ} \mathrm{C}(1,960 \mathrm{~g})$, the samples were injected into the triple quadrupole LC-MS/ MS (liquid chromatography-tandem mass spectroscopy) system (guard column: Phenomenex MAX-RP; 4× $2.0 \mathrm{~mm}$, Brechbühler, Schlieren, Switzerland; main column: Phenomenex Synergy $4 \mu$ MAX-RP; $2.0 \times$ $50 \mathrm{~mm}$, Brechbühler). Two mobile phases [phase A: $\mathrm{H}_{2} \mathrm{O}+30 \mathrm{mM} \mathrm{NH} \mathrm{N}_{4} \mathrm{OAc}, \mathrm{pH}$ 4, phase $\mathrm{B}: \mathrm{MeOH} / \mathrm{H}_{2} \mathrm{O}$ $\left.100 / 3(\mathrm{v} / \mathrm{v})+30 \mathrm{mM} \mathrm{NH} \mathrm{N}_{4} \mathrm{OAc}, \mathrm{pH}=4\right]$ were used for elution. Detection was performed after electrospray ionization (API 4000 from MDS Sciex). For parent idebenone, the transition $\mathrm{m} / \mathrm{z} 339$ to 197 was used. The lower limit of quantification (LLQ) of parent idebenone was $0.5 \mathrm{ng} / \mathrm{mL}$. Accuracy and precision were $106.0-107.2 \%$ and $4.6-$ $7.5 \%$, respectively. The correlation coefficients of the calibration curves were $\geq 0.992$ for parent idebenone (concentration range tested $0.5-50 \mathrm{ng} / \mathrm{ml}$ ).

Total idebenone and total metabolites in plasma After thawing, $180 \mu \mathrm{L}$ of internal standard (deuterium-labeled idebenone and deuterium-labeled metabolites in aqueous $\mathrm{NH}_{4} \mathrm{OAc}$ buffer; $\mathrm{pH}$ 4.6) were added to $200-\mu \mathrm{L}$ plasma samples. After deconjugation [incubation at $37^{\circ} \mathrm{C}$ for $4 \mathrm{~h}$ after adding $20 \mu \mathrm{l}$ of a glucuronidase/sulfatase-containing enzyme solution from Helix pomatia (Roche Diagnostics, Penzberg, Germany)], $200 \mu 16 \mathrm{M}$ hydrochloric acid was added, and the samples were incubated again at $70^{\circ} \mathrm{C}$ for $30 \mathrm{~min}$. After cooling to room temperature, $1.0 \mathrm{~mL}$ ethyl acetate/hexane $(4 / 1, v / v)$ was added and the samples were thoroughly mixed and centrifuged $(1,910 \mathrm{~g})$. The resulting supernatant was separated and evaporated. The residue 
was reconstituted and inserted into the LC-MS/MS system. Detection was performed after electrospray ionization (API 365 from MDS Sciex), and the following transitions were used: for QS10 m/z 353 to 275, for QS6 m/ z 297 to 235, for QS4 m/z 269 to 207. The lower limit of quantification (LLQ) for total idebenone, total QS10, and total QS4 in plasma was $50 \mathrm{ng} / \mathrm{mL}$; for total QS6, it was $25 \mathrm{ng} / \mathrm{mL}$. Accuracy and precision for total idebenone and its metabolites QS10, QS6, and QS4 were 97.7$101.7 \%$ and $5.2-8.0 \%$, respectively. The correlation coefficients of the calibration curves were $\geq 0.992$ for total idebenone and all metabolites (concentration range $25-20,000 \mathrm{ng} / \mathrm{mL})$.

Total idebenone and total metabolites in urine Samples were prepared and inserted into the LC-MS/MS system as described above. The LLQ was $200 \mathrm{ng} / \mathrm{mL}$ for all analytes. Accuracy and precision were $100.2-109.2 \%$ and $2.1-6.8 \%$, respectively. The calibration range for total idebenone and metabolites was $200-40,000 \mathrm{ng} / \mathrm{ml}$. The correlation coefficients of the calibration curves were above 0.994 for all analytes.

\section{Pharmacokinetic analysis}

The pharmacokinetic parameters of parent and total idebenone as well of its metabolites total QS10, total QS6, and total QS4 in plasma were calculated according to noncompartmental standard pharmacokinetic methods. As the plasma concentrations of parent idebenone were very low, only a limited pharmacokinetic analysis for parent idebenone was possible. The following parameters were determined from the plasma concentration-time profile: area under the curve from time zero to the last sampling time at which the concentration was at or above the lower limit of quantification $\left(\mathrm{AUC}_{0-\mathrm{t}}\right)$, maximum plasma concentration observed $\left(\mathrm{C}_{\max }\right)$, and time to reach maximum plasma concentration $\left(\mathrm{t}_{\max }\right)$.

For total idebenone and its metabolites total QS10, total QS6, and total QS4, the following parameters were determined from plasma concentration and urine concentration data: $C_{\max }, t_{\max }$, the terminal rate constant $\left(\lambda_{z}\right.$; determined from the terminal slope of the log-transformed plasma concentration curve using linear regression on terminal data points using WinNonlin Software, version 5.1, Pharsight, Mountain View, CA, USA), $\mathrm{AUC}_{0-\mathrm{t}}$, area under the plasma concentration-time curve from time zero to infinity $\left(\mathrm{AUC}_{0-\infty} ; \mathrm{AUC}_{0-\mathrm{t}}+\mathrm{C}_{\text {last }} / \lambda_{\mathrm{z}}\right)$, area under the curve within a dosing interval under repeated administration of idebenone $\left(\mathrm{AUC}_{\tau}\right)$, apparent terminal half-life $\left(\mathrm{t}_{1 / 2}\right.$; calculated as $\ln 2 / \lambda_{z}$ ), area under the plasma concentrationtime curve from the last measurement point above the limit of quantification to infinity $\left(\mathrm{AUC}_{\text {extra }}\right)$, urinary excretion from time zero to the last urinary collection time after a single oral administration of idebenone $\left(\mathrm{Ae}_{0-96 \mathrm{~h}}\right)$, and urinary excretion within a dosing interval under repeated administration of idebenone $\left(\mathrm{Ae}_{\tau}\right)$.

If the value for $\mathrm{AUC}_{\text {extra }}$ provided more than $20 \%$ of $\mathrm{AUC}_{0-\infty}, \mathrm{AUC}_{0-\infty}$ and all values derived from $\lambda_{\mathrm{z}}$ were rejected as implausible and not included in further statistical analysis. In cases where the actual sampling time deviated more than $5 \%$ in either direction from scheduled sampling time points, the actual sampling times were used. Plasma concentrations below the lower limit of quantification were taken as zero for calculating the AUC. Plasma concentrations below the lower limit of quantification that occurred after the last quantifiable data point were handled as missing values for calculating $\lambda_{z}, C_{\max }$, and $t_{\max }$, and were compiled from raw data. The other pharmacokinetic parameters for total idebenone and for the total metabolites after single and repeated administrations were calculated using WinNonlin Software (version 5.1). The noncompartmental option was used to estimate the terminal elimination rate constants and the area under the plasma concentration-time curve $\left(\mathrm{AUC}_{\tau}\right)$ as well as $\mathrm{AUC}_{0-\infty}$. Urinary excretion of total idebenone and the metabolites total QS10, total QS6, and total QS4 was calculated as $\mathrm{U} \times \mathrm{V}=\mathrm{Ae}$, where $\mathrm{U}=$ urinary concentration of the analyte, $\mathrm{V}=$ urinary volume per hour, and $\mathrm{Ae}=$ urinary excretion of the analyte per hour. Descriptive statistics were used to summarize all pharmacokinetic parameters.

Dose-proportionality of pharmacokinetic data of free idebenone was assessed by comparing dose-normalized AUC and $\mathrm{C}_{\max }$ values after first dose and in steady-state using analysis of variance (SPSS for Windows, version 15.0). Level of significance was $\mathrm{P}=0.05$.

\section{Results}

Subjects

Twenty-six subjects were enrolled in the study; 14 subjects were assigned to receive the $150-\mathrm{mg}$ dose of idebenone (group A) and 12 subjects were assigned to receive the 750-mg dose (group B). Mean ages and weights $( \pm$ SD) of participants were $24.3 \pm 4.1$ years and $72.0 \pm 8.1 \mathrm{~kg}$ in group A and $25.8 \pm 3.2$ years and $74.9 \pm$ $6.6 \mathrm{~kg}$ in group $\mathrm{B}$, respectively. All but one subject completed the study; this subject discontinued after the first $150-\mathrm{mg}$ dose of idebenone owing to arterial hypertension and was not evaluable for pharmacokinetic parameters. One subject participated in both dosing groups in the study. 
Pharmacokinetics of idebenone following single and multiple doses

Main pharmacokinetic parameters $\mathrm{C}_{\max }, \mathrm{t}_{\max }$, and $\mathrm{AUC}_{0-\mathrm{t}}$ of parent and total idebenone are shown in Table 1. After single oral administrations of $150 \mathrm{mg}$ or $750 \mathrm{mg}$ idebenone, $\mathrm{C}_{\max }$ values of parent idebenone peaked in plasma within $2 \mathrm{~h}$ on average and were highly variable. Plasma concentrations rarely exceeded the LLQ, indicating that parent idebenone is rapidly metabolized.

During repeated dosing of both $150 \mathrm{mg}$ three times daily and $750 \mathrm{mg}$ three times daily, the pre-dose plasma concentrations of parent idebenone were below or only slightly above the lower limit of quantification at both dose levels. The average $\mathrm{C}_{\max }$ increased 1.2-fold and the average $\mathrm{AUC}_{0-\mathrm{t}}$ 1.3-fold after repeated dosing of the 150-mg dose, and 1.4fold and 1.1-fold, respectively, after repeated dosing of the 750-mg dose, indicating that there was no relevant accumulation of the drug. $\mathrm{C}_{\max }$ and $\mathrm{AUC}_{0-\mathrm{t}}$ were between 4 and 7 times higher for the 750-mg dose compared to the $150-\mathrm{mg}$ dose. Dose-normalized values of $\mathrm{C}_{\max }$ and $\mathrm{AUC}$ were not significantly different between the dose groups indicating approximately linear pharmacokinetics.

Mean plasma concentrations of total idebenone and its total metabolites after single and repeated dosing are presented for the 150-mg-dose group (Fig. 2) and 750-mgdose group (Fig. 3). Average plasma concentrations were highest for total idebenone and total QS4 (Tables 1 and 2); total idebenone reached plasma concentrations 420 - to 650- fold higher than parent idebenone following single and multiple doses of $150 \mathrm{mg}$ or $750 \mathrm{mg}$. $\mathrm{AUC}_{0-\mathrm{t}}$ values of total idebenone and total QS4 were approximately 1,000 times higher than $\mathrm{AUC}_{0-\mathrm{t}}$ values of parent idebenone at both doses (Table 1). AUC values of total QS10 were approximately $50 \%$ of the AUC values of total QS4. Plasma concentrations of total QS6 were nearly 50\% lower than those of total QS10 (Table 2). Similarly to the pharmacokinetic profile of parent idebenone, there was no clinically relevant accumulation of total metabolites during repeated dosing, and $\mathrm{C}_{\max }$ and $\mathrm{AUC}$ values increased nearly linearly with dose. The half-lives of total idebenone and total QS4 tended to increase with repeated dosing.

\section{Urinary excretion of total metabolites}

After single and repeated oral administrations of $150 \mathrm{mg}$ idebenone, approximately $50 \%$ of drug-derived material was excreted in urine as the conjugated metabolites of QS4 (40\%), QS6 (6\%), QS10 (<1\%), and idebenone $(<1 \%)$ (Table 3). At the 750-mg dose, urinary excretion of the conjugated metabolites amounted to approximately $50 \%$ of QS4, 9\% of QS6, 1.5\% of QS10, and $<1 \%$ of idebenone (Table 3).

\section{Safety and tolerability}

After a single oral administration of $150 \mathrm{mg}$ idebenone, 6/14 subjects reported adverse events (AEs) of mild to moderate

Table 1 Pharmacokinetic parameters of pharmacologically active parent idebenone and total idebenone in plasma after single and multiple oral doses of idebenone

\begin{tabular}{|c|c|c|c|c|c|c|c|}
\hline \multirow[b]{2}{*}{ PK parameters } & \multicolumn{3}{|c|}{ Parent idebenone } & \multicolumn{4}{|l|}{ Total idebenone } \\
\hline & $\mathrm{C}_{\max }(\mathrm{ng} / \mathrm{mL})$ & $\mathrm{t}_{\max }(\mathrm{h})$ & $\mathrm{AUC}_{0-\mathrm{t}}(\mathrm{h} \cdot \mathrm{ng} / \mathrm{mL})$ & $\mathrm{C}_{\max }(\mathrm{ng} / \mathrm{mL})$ & $\mathrm{t}_{\max }(\mathrm{h})$ & $\mathrm{AUC}_{0-\mathrm{t}}(\mathrm{h} \cdot \mathrm{ng} / \mathrm{mL})$ & $\mathrm{t}_{1 / 2}(\mathrm{~h})$ \\
\hline \multicolumn{8}{|c|}{$150 \mathrm{mg}$ in a single dose } \\
\hline Mean & 5.8 & 0.87 & 5.5 & 1,631 & 1.33 & 6,277 & 3.10 \\
\hline SD & 4.6 & 0.55 & 3.7 & 516 & 0.68 & 2,619 & 2.29 \\
\hline Range & $0.8-16.8$ & $0.33-2.00$ & $0.8-14.6$ & $881-3,003$ & $0.67-3.00$ & $3,510-12,919$ & $1.55-10.05$ \\
\hline \multicolumn{8}{|c|}{$150 \mathrm{mg}$ given tid for 2 weeks ( $450 \mathrm{mg}$ total daily dose) } \\
\hline Mean & 6.0 & 0.67 & 6.0 & 2,061 & 1.83 & 7,322 & 8.14 \\
\hline SD & 6.3 & 0.19 & 4.7 & 868 & 1.19 & 3,282 & 4.64 \\
\hline Range & $1.1-22.5$ & $0.33-1.0$ & $1.6-15.2$ & $958-4,173$ & $0.67-5.00$ & $4,248-17,455$ & $2.69-16.72$ \\
\hline \multicolumn{8}{|c|}{$750 \mathrm{mg}$ in a single dose } \\
\hline Mean & 23.6 & 2.13 & 37.9 & 5,229 & 2.43 & 32,757 & 10.80 \\
\hline $\mathrm{SD}$ & 24.8 & 1.99 & 18.0 & 1,683 & 1.27 & 12,296 & 3.71 \\
\hline Range & $5.3-93.7$ & $0.33-6.00$ & $20.6-68.2$ & $2,821-8,784$ & $1.00-5.00$ & $14,481-60,499$ & $4.59-16.87$ \\
\hline \multicolumn{8}{|c|}{$750 \mathrm{mg}$ given tid for 2 weeks $(2,250 \mathrm{mg}$ total daily dose $)$} \\
\hline Mean & 22.4 & 1.06 & 39.2 & 8,158 & 1.93 & 32221 & 15.08 \\
\hline SD & 13.5 & 0.85 & 19.2 & 1,978 & 0.80 & 10142 & 4.47 \\
\hline Range & 8.147 .5 & $0.33-3.0$ & $18.5-81.6$ & $5,320-11,400$ & $1.33-3.50$ & $16,214-46,620$ & $5.31-21.94$ \\
\hline
\end{tabular}

$C_{\max }$ Maximum plasma concentration, $t_{\max }$ time to reach $\mathrm{C}_{\max }, A U C_{0-t}$ area under the plasma drug concentration-time curve from time zero to the last sampling time at which the concentration was at or above the lower limit of quantification, $t_{1 / 2}$ elimination half-life, tid three times daily, $S D$ standard deviation 

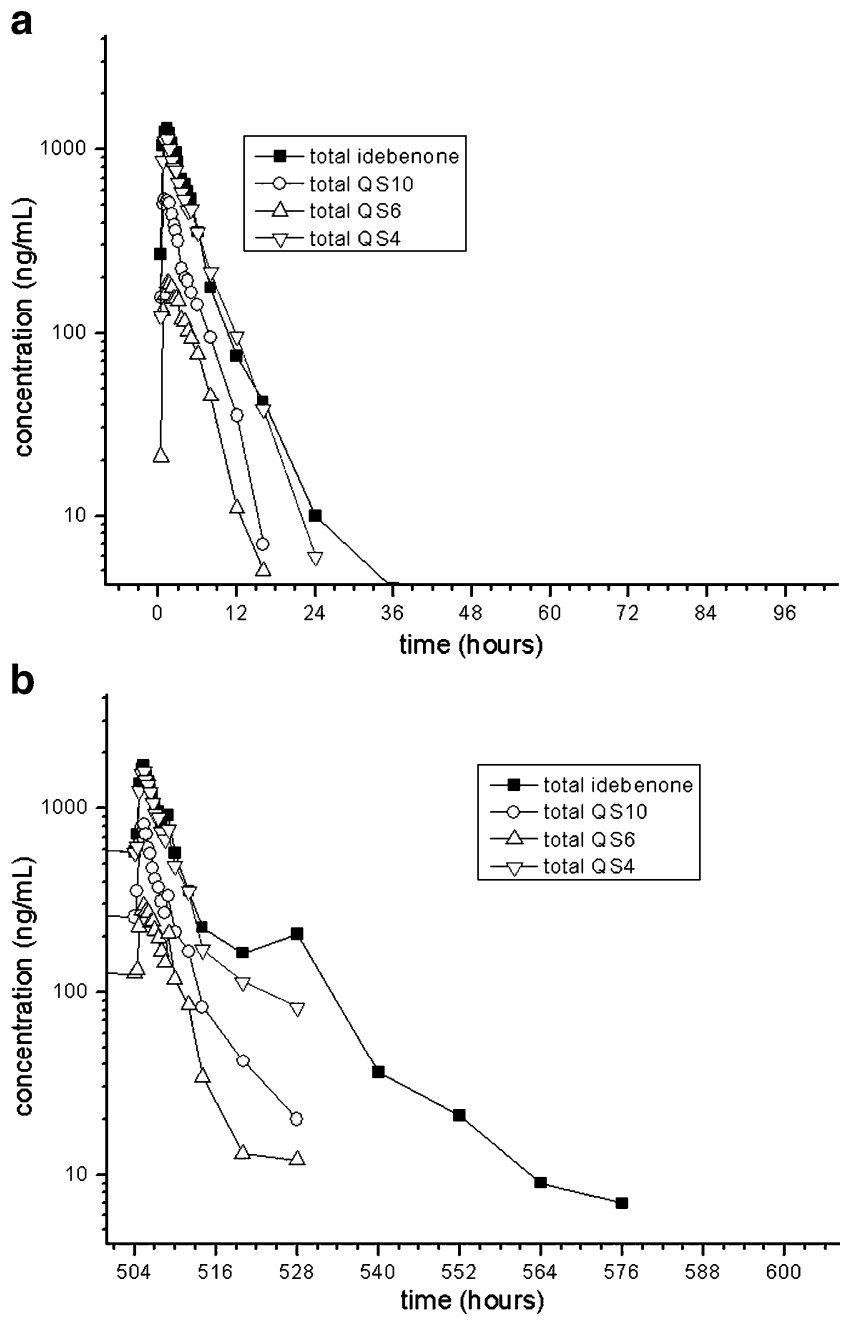

Fig. 2 Mean plasma concentrations of total idebenone and its total metabolites after single and repeated oral doses of $150 \mathrm{mg}$ idebenone in healthy male subjects. a After a single dose and $\mathbf{b}$ in steady state

severity. One subject had to be withdrawn from the study after the very first drug administration because of arterial hypertension. Although it was reported at the screening visit that he suffered from "white-coat" hypertension, the investigator judged that the hypertension was probably related to the study medication. During repeated administration of $150 \mathrm{mg}$ idebenone, 10/13 subjects reported AEs. Four subjects reported gastrointestinal AEs and three reported headaches. The other AEs occurred generally as single events, including one subject who reported discoloration of the urine. After a single oral administration of $750 \mathrm{mg}$ idebenone, AEs were reported in $1 / 12$ subjects (dizziness and migraine). During repeated administrations of $750 \mathrm{mg}$ idebenone, 11/12 subjects reported AEs. Discoloration of the urine $(n=6)$, gastrointestinal AEs $(n=5)$, and headache $(n=4)$ were most commonly reported. There were no clinically relevant changes in laboratory values, vital signs, or ECG morphology and QTc-duration at either dose level.

\section{Discussion}

Idebenone was quickly absorbed and metabolized in this population of healthy adult men. There was high intersubject variability in plasma concentrations of pharmacologically active parent idebenone after both single and repeated oral doses of $150 \mathrm{mg}$ tid and $750 \mathrm{mg}$ tid. Due to the low number of plasma concentrations above the lower limit of quantification following both single and repeated doses of idebenone, the apparent elimination half-life andAUC ${ }_{0-\infty}$ values of parent idebenone could not be calculated. Total idebenone exhibited linear pharmacokinetics over the dose range tested. There was no indication of accumulation of parent idebenone after repeated doses, which is consistent with results previously reported for total idebenone [23, 24].

The idebenone metabolites (QS10, QS6, and QS4) appeared in the plasma almost synchronously with parent
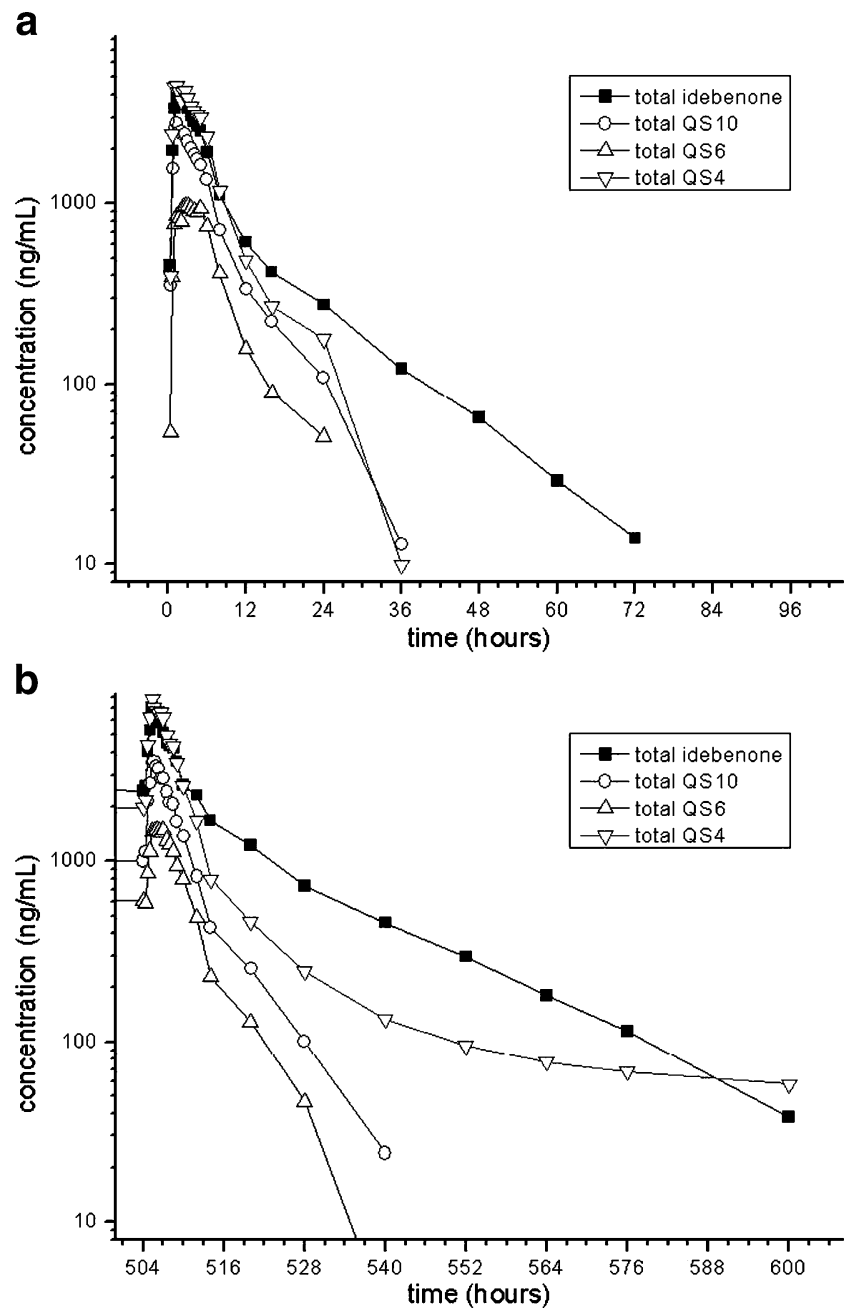

Fig. 3 Mean plasma concentrations of total idebenone and its total metabolites after single and repeated oral doses of $750 \mathrm{mg}$ idebenone in healthy male subjects. a After a single dose and $\mathbf{b}$ in steady state 
Table 2 Pharmacokinetic parameters of total QS10, total QS6, and total QS4 in plasma after single and multiple oral doses of idebenone

\begin{tabular}{|c|c|c|c|c|c|c|c|c|c|}
\hline \multirow[b]{2}{*}{ PK parameters } & \multicolumn{3}{|l|}{ Total QS10 } & \multicolumn{3}{|l|}{ Total QS6 } & \multicolumn{3}{|l|}{ Total QS4 } \\
\hline & $\begin{array}{l}\mathrm{C}_{\max } \\
(\mathrm{ng} / \mathrm{mL})\end{array}$ & $\begin{array}{l}\mathrm{AUC}_{0-\mathrm{t}} \\
(\mathrm{h} \cdot \mathrm{ng} / \mathrm{mL})\end{array}$ & $\mathrm{t}_{1 / 2}(\mathrm{~h})$ & $\begin{array}{l}\mathrm{C}_{\max } \\
(\mathrm{ng} / \mathrm{mL})\end{array}$ & $\begin{array}{l}\mathrm{AUC}_{0-\mathrm{t}} \\
(\mathrm{h} \cdot \mathrm{ng} / \mathrm{mL})\end{array}$ & $\mathrm{t}_{1 / 2}(\mathrm{~h})$ & $\begin{array}{l}\mathrm{C}_{\max } \\
(\mathrm{ng} / \mathrm{mL})\end{array}$ & $\begin{array}{l}\mathrm{AUC}_{0-\mathrm{t}} \\
(\mathrm{h} \cdot \mathrm{ng} / \mathrm{mL})\end{array}$ & $\mathrm{t}_{1 / 2}(\mathrm{~h})$ \\
\hline \multicolumn{10}{|c|}{$150 \mathrm{mg}$ in a single dose } \\
\hline Mean & 744 & 2576 & 3.02 & 258 & 1889 & 3.57 & 1459 & 5635 & 3.54 \\
\hline SD & 390 & 1117 & 1.54 & 116 & 776 & 1.37 & 632 & 1046 & 1.35 \\
\hline Range & $285-1462$ & $777-4424$ & $0.72-6.10$ & $111-403$ & $1111-3310$ & $2.30-7.46$ & $667-2355$ & $3559-7086$ & $1.96-7.24$ \\
\hline \multicolumn{10}{|c|}{$150 \mathrm{mg}$ given tid for 2 weeks ( $450 \mathrm{mg}$ total daily dose) } \\
\hline Mean & 990 & 3087 & 5.02 & 396 & 1436 & 3.67 & 1899 & 6653 & 4.28 \\
\hline SD & 383 & 1180 & 2.90 & 197 & 408 & 1.69 & 666 & 1544 & 1.92 \\
\hline Range & $611-1952$ & $2076-6324$ & $1.61-12.74$ & $194-944$ & $895-2293$ & $2.14-8.44$ & $1103-2970$ & $4151-9668$ & $2.52-9.11$ \\
\hline \multicolumn{10}{|c|}{$750 \mathrm{mg}$ in a single dose } \\
\hline Mean & 3932 & 18725 & 7.66 & 1519 & 8868 & 5.58 & 6884 & 30591 & 4.15 \\
\hline SD & 1455 & 5566 & 4.08 & 492 & 2463 & 5.85 & 3526 & 7027 & 2.08 \\
\hline Range & $1677-5760$ & 11961-29731 & $2.03-18.15$ & $882-2593$ & $4739-12105$ & $2.12-23.03$ & $3472-16700$ & $21630-44069$ & $2.24-8.04$ \\
\hline \multicolumn{10}{|c|}{$750 \mathrm{mg}$ given tid for 2 weeks $(2,250 \mathrm{mg}$ total daily dose $)$} \\
\hline Mean & 4387 & 16300 & 6.32 & 1946 & 8262 & 4.26 & 9653 & 33837 & 32.49 \\
\hline SD & 1267 & 5204 & 1.95 & 532 & 2626 & 1.94 & 1585 & 5508 & 18.08 \\
\hline Range & $2717-7653$ & $10584-26582$ & $3.95-11.19$ & $1300-3157$ & $5053-12300$ & $2.27-9.22$ & $6886-12760$ & $25524-43930$ & $12.18-78.36$ \\
\hline
\end{tabular}

$C_{\max }$ Maximum plasma concentration, $t_{\max }$ time to reach $\mathrm{C}_{\max }, A U C_{0-t}$ area under the plasma drug concentration-time curve from time zero to the last sampling time at which the concentration was at or above the lower limit of quantification, $t_{1 / 2}$ elimination half-life, tid three times daily, $S D$ standard deviation

idebenone, indicating that idebenone was rapidly metabolized, undergoing conjugation and side-chain shortening. Total idebenone reached plasma concentrations nearly 1,000 -fold higher than those of parent idebenone after single and repeated oral doses at both dose levels; the high first-pass effect (99\%) observed in this study is consistent with previously published results using lower doses of idebenone [22]. The $\mathrm{C}_{\max }$ ratios between the 750 -mg dose and the 150-mg dose of idebenone for most of the metabolites following single and multiple doses were close to 5 , indicating linear pharmacokinetics consistent with those observed for parent idebenone.

The analysis of the urinary data revealed that total QS4 was the prominent drug-derived material in urine. It

Table 3 Urinary excretion of total idebenone, total QS10, total QS6, and total QS4 in plasma after single and multiple oral doses of idebenone

\begin{tabular}{|c|c|c|c|c|}
\hline Urinary excretion (mg) & Total idebenone & Total QS10 & Total QS6 & Total QS4 \\
\hline \multicolumn{5}{|l|}{$150 \mathrm{mg}$ in a single dose } \\
\hline Mean & 0.7 & 1.4 & 9.5 & 68.1 \\
\hline SD & 0.3 & 0.7 & 3.8 & 20.6 \\
\hline Range & $0.3-1.3$ & $0.5-3.3$ & $5.6-20.6$ & $32.3-116.6$ \\
\hline \multicolumn{5}{|c|}{$150 \mathrm{mg}$ given tid for 2 weeks ( $450 \mathrm{mg}$ total daily dose) } \\
\hline Mean & 0.8 & 1.3 & 8.7 & 58.8 \\
\hline SD & 0.4 & 0.6 & 3.5 & 20.5 \\
\hline Range & $0.4-1.6$ & $0.6-2.6$ & $3.3-13.9$ & $20.7-94.6$ \\
\hline \multicolumn{5}{|l|}{$750 \mathrm{mg}$ in a single dose } \\
\hline Mean & 5.6 & 9.9 & 56.8 & 359.2 \\
\hline SD & 2.7 & 3.7 & 18.6 & 63.3 \\
\hline Range & $2.7-13.2$ & $4.6-15.9$ & $31.2-100.4$ & $266.6-466.1$ \\
\hline \multicolumn{5}{|c|}{$750 \mathrm{mg}$ given tid for 2 weeks $(2,250 \mathrm{mg}$ total daily dose $)$} \\
\hline Mean & 7.1 & 10.1 & 65.2 & 407.4 \\
\hline SD & 3.5 & 4.0 & 25.4 & 126.2 \\
\hline Range & $3.0-15.5$ & $4.5-17.9$ & $20.7-119.4$ & $187.8-700.9$ \\
\hline
\end{tabular}

tid Three times daily, $S D$ standard deviation 
represented nearly $50 \%$ of the drug administered. The second highest fraction in urine was total QS6. The percentage of urinary-detectable metabolites also reflected the water solubility of idebenone as the most lipophilic compound in this compound group and QS4 as the most hydrophilic metabolite. Urinary data indicate that a substantial part of the drug-derived material is excreted by the kidneys.

Idebenone was generally safe and showed only adverse events of mild to moderate intensity in this population of healthy adult males. The most frequently reported adverse events were gastrointestinal in nature; however, no patient discontinued from the study as a result of these events. A dose-dependent increase in the incidence of chromaturia was observed; this is a known phenomenon likely owing to the renal excretion of idebenone metabolites [9] and was also reported in a recent clinical trial that evaluated the pharmacokinetics and efficacy of idebenone $60 \mathrm{mg} \mathrm{kg}^{-1}$ $\mathrm{day}^{-1}$ given for 1 month [23]. No serious adverse events or clinically relevant changes in laboratory values, vital signs, or ECG parameters were noted.

Limitations of this study include the fact that the low bioavailability of parent idebenone limited the characterization of its pharmacokinetic profile, and that there was high intersubject variability in pharmacokinetic parameters of parent idebenone. This may make it difficult to extrapolate these results generally to other populations. However, results from a recent study in young FA patients showed an idebenone pharmacokinetic profile similar to that reported here [23].

In summary, idebenone in daily doses up to $2,250 \mathrm{mg}$ was safe and well tolerated in healthy adult men. Total idebenone exhibited linear pharmacokinetics over the dose range tested. Parent idebenone was subject to a large firstpass effect, limiting the amount of pharmacologically active parent idebenone present in the plasma.

Several studies have suggested that idebenone may improve cardiological symptoms of FA [15-17]. However, these studies generally used lower doses than those examined here, and therefore, patients may not have achieved sufficiently high plasma and subsequently brain levels of pharmacologically active parent idebenone. As can be seen in our study, even with comparably high doses, only low plasma concentrations of idebenone could be achieved. In previous work, it has been speculated that high doses of idebenone might be needed to see changes in neurological symptoms or disease progression of FA [16, $18,19,21]$. As shown in animal experiments, idebenone does cross the blood-brain barrier and distributes in brain tissue, with a significant amount (34\%) localized in mitochondria [25].

Taken together, our results suggest that both efficacy and safety of higher doses of idebenone need to be evaluated in controlled clinical trials in patients with FA. These trials are currently ongoing and should help determine the appropriate efficacious dose of idebenone in this population.

\section{References}

1. Durr A, Cossee M, Agid Y, Campuzano V, Mignard C, Penet C, Mandel JL, Brice A, Koenig M (1996) Clinical and genetic abnormalities in patients with Friedreich's ataxia. N Engl J Med 335:1169-1175

2. Campuzano V, Montermini L, Molto MD, Pianese L, Cossee M, Cavalcanti F, Monros E, Rodius F, Duclos F, Monticelli A, Zara F, Canizares J, Koutnikova H, Bidichandani SI, Gellera C, Brice A, Trouillas P, De Michele G, Filla A, De Frutos R, Palau F, Patel PI, Di Donato S, Mandel JL, Cocozza S, Koenig M, Pandolfo M (1996) Friedreich's ataxia: autosomal recessive disease caused by an intronic GAA triplet repeat expansion. Science 271:1423-1427

3. Rötig A, Sidi D, Munnich A, Rustin P (2002) Molecular insights into Friedreich's ataxia and antioxidant-based therapies. Trends Mol Med 8:221-224

4. Pandolfo M (2008) Friedreich ataxia. Arch Neurol 65:1296-1303

5. Lodi R, Cooper JM, Bradley JL, Manners D, Styles P, Taylor DJ, Schapira AH (1999) Deficit of in vivo mitochondrial ATP production in patients with Friedreich ataxia. Proc Natl Acad Sci USA 96:11492-11495

6. Schulz JB, Dehmer T, Schols L, Mende H, Hardt C, Vorgerd M, Burk K, Matson W, Dichgans J, Beal MF, Bogdanov MB (2000) Oxidative stress in patients with Friedreich ataxia. Neurology 55:1719-1721

7. Di Prospero NA, Fischbeck KH (2005) Therapeutics development for triplet repeat expansion diseases. Nat Rev 6:756-765

8. Suno M, Nagaoka A (1984) Inhibition of lipid peroxidation by a novel compound, idebenone (CV-2619). Jap J Pharmacol 35:196198

9. Zs-Nagy I (1990) Chemistry, toxicology, pharmacology and pharmacokinetics of idebenone: a review. Arch Gerontol Geriatr 11:177-186

10. Sugiyama Y, Fujita T (1985) Stimulation of the respiratory and phosphorylating activities in rat brain mitochondria by idebenone (CV-2619), a new agent improving cerebral metabolism. FEBS Lett 184:48-51

11. Gillis JC, Benefield P, McTavish D (1994) Idebenone. A review of its pharmacodynamic and pharmacokinetic properties, and therapeutic use in age-related cognitive disorders. Drugs Aging 5:133152

12. Gutzmann H, Hadler D (1998) Sustained efficacy and safety of idebenone in the treatment of Alzheimer's disease: update on a 2year double-blind multicentre study. J Neural Transm Suppl 54:301-310

13. Thal LJ, Grundman M, Berg J, Ernstrom K, Margolin R, Pfeiffer E, Weiner MF, Zamrini E, Thomas RG (2003) Idebenone treatment fails to slow cognitive decline in Alzheimer's disease. Neurology 61:1498-1502

14. Weyer G, Babej-Dolle RM, Hadler D, Hofmann S, Herrmann WM (1997) A controlled study of 2 doses of idebenone in the treatment of Alzheimer's disease. Neuropsychobiol 36:73-82

15. Buyse G, Mertens L, Di Salvo G, Matthijs I, Weidemann F, Eyskens B, Goossens W, Goemans N, Sutherland GR, Van Hove JL (2003) Idebenone treatment in Friedreich's ataxia: neurological, cardiac, and biochemical monitoring. Neurology 60:16791681 
16. Hausse AO, Aggoun Y, Bonnet D, Sidi D, Munnich A, Rotig A, Rustin P (2002) Idebenone and reduced cardiac hypertrophy in Friedreich's ataxia. Heart 87:346-349

17. Mariotti C, Solari A, Torta D, Marano L, Fiorentini C, Di Donato S (2003) Idebenone treatment in Friedreich patients: one-year-long randomized placebo-controlled trial. Neurology 60:1676-1679

18. Arnold P, Boulat O, Maire R, Kuntzer T (2006) Expanding view of phenotype and oxidative stress in Friedreich's ataxia patients with and without idebenone. Schweiz Arch Neurol Psychiatr 157:169-176

19. Artuch R, Aracil A, Mas A, Colome C, Rissech M, Monros E, Pineda M (2002) Friedreich's ataxia: idebenone treatment in early stage patients. Neuropediatrics 33:190-193

20. Rustin P, Rötig A, Munnich A, Sidi D (2002) Heart hypertrophy and function are improved by idebenone in Friedreich's ataxia. Free Radical Res 36:467-469

21. Di Prospero N, Baker A, Jeffries N, Fischbeck KH (2007) Neurological effects of high-dose idebenone in patients with
Friedreich's ataxia: a randomised, placebo-controlled trial. Lancet Neurol 6:878-886

22. Kobayashi T, Yoshida K, Mitani M, Torii H, Tanayama S (1985) Metabolism of idebenone (CV-2619), a new cerebral metabolism improving agent: isolation and identification of metabolites in the rat and dog. J Pharmacobiodyn 8:448-456

23. Boni J, Maugeri A, Zingali G, Ramelli L, Gherardi S (1992) Steady-state pharmacokinetics of idebenone in healthy volunteers. Arch Gerontol Geriatr 15:197-205

24. Pisano P, Durand A, Autret E, Desnuelle C, Pinsard N, Serratrice G, Legout V, Joubert M, Blin O (1996) Plasma concentrations and pharmacokinetics of idebenone and its metabolites following single and repeated doses in young patients with mitochondrial encephalomyopathy. Eur J Clin Pharmacol 51:167-169

25. Torii H, Yoshida K, Kobayashi T, Tsukamoto T, Tanayama S (1985) Disposition of idebenone (CV-2619), a new cerebral metabolism improving agent, in rats and dogs. J Pharmacobiodyn $8: 457-467$ 